\begin{tabular}{|c|l|}
\hline Title & $\begin{array}{l}\text { Oxidation of hydrophobic alcohol susing aqueous hy drogen peroxide over amphiphilic silica particles loaded with } \\
\text { titanium(IV) oxide as a liquid-liquid phase boundary catalyst }\end{array}$ \\
\hline Author(s) & Choi, Kwang-Min; Ikeda, Shigeru; Ishino, Satoru; Ikeue, Keita; Matsumura, Michio; Ohtani, Bunsho \\
\hline Citation & $\begin{array}{l}\text { A pplied Catalysis A General, 278(2), 269-274 } \\
\text { https://doi.org/10.1016/.apcata.2004.10.006 }\end{array}$ \\
\hline Issue Date & 2005-01-10 \\
\hline Doc URL & http://hdl.handle.net/2115/14643 \\
\hline Type & article (author version) \\
\hline File Information & ACA G2005-278-2.pdf \\
\hline
\end{tabular}

Instructions for use 


\title{
Oxidation of hydrophobic alcohols using aqueous hydrogen peroxide over amphiphilic silica particles loaded with titanium(IV) oxide as a liquid-liquid phase-boundary catalyst
}

Kwang-Min CHOI, ${ }^{\mathrm{a}}$ Shigeru IKEDA, ${ }^{\mathrm{a}, \mathrm{b}}$ Satoru ISHINO, ${ }^{\mathrm{b}}$ Keita IKEUE, ${ }^{\mathrm{a}}$ Michio MATSUMURA, ${ }^{\mathrm{b}}$ and Bunsho OHTANI ${ }^{\mathrm{c}^{*}}$

" "Conversion and Control by Advanced Chemistry", PRESTO, Japan Science and Technology Agency (JST), 4-1-8 Honcho, Kawaguchi 332-0012, Japan

${ }^{\mathrm{b}}$ Research Center for Solar Energy Chemistry, Osaka University, 1-3 Machikaneyama, Toyonaka, Osaka 560-8531, Japan

${ }^{c}$ Catalysis Research Center, Hokkaido University, Sapporo 001-0021, Japan

\begin{abstract}
Phase-boundary catalysis (PBC), a new concept of a heterogeneous catalytic system for oxidation of various hydrophobic alcohols with aqueous hydrogen peroxide $\left(\mathrm{H}_{2} \mathrm{O}_{2}\right)$ has been investigated. A part the external surface of silica $\left(\mathrm{SiO}_{2}\right)$ particles loaded with titanium(IV) oxides was modified with hydrophobic alkyl groups to obtain amphiphilic particles, having both hydrophobic and hydrophilic surfaces on each particle. The amphiphilic particles were spontaneously assembled at interfaces between dual phase mixtures of aqueous solutions and water-immiscible organic compounds. Upon addition to a dual phase mixture of aqueous $\mathrm{H}_{2} \mathrm{O}_{2}$ and toluene-containing hydrophobic alcohols, these particles acted as an efficient catalyst for the reaction to produce corresponding aldehydes and ketones selectively. Notable features of the PBC system are that the oxidation proceeds even without agitation and that only a few percent of titanium species was detected as dissolved species. Productions of aldehydes and
\end{abstract}


ketones were also observed when titanium loaded $\mathrm{SiO}_{2}$ without modification with alkyl groups was employed for the reaction. However, a large amount of loaded titanium on the material was leached during the reaction. These results indicate that surface-covered alkyl groups not only bring about effective contact with hydrophobic alcohols in the organic phase but also give stability against leaching, leading to heterogeneous catalytic functions.

\section{Keywords}

liquid-phase oxidation, hydrophobic alcohols, asymmetric surface modification, amphiphilic solid catalyst, phase boundary, titanium, leaching

*Corresponding author.

Tel: +81-11-706-9132; fax; +81-11-706-9133

E-mail address: ohtani@cat.hokudai.ac.jp 


\section{Introduction}

Heterogeneous catalytic oxidation of organic compounds such as alkenes and alcohols in liquid phase has attracted much attention as a promising strategy for environmentally benign organic synthesis [1,2]. A wide variety of oxidants can be used for such reactions. Hydrogen peroxide $\left(\mathrm{H}_{2} \mathrm{O}_{2}\right)$ is an ideal one because of its high content of active oxygen, availability, nontoxicity, and non-polluting property, i.e., it produces only water as a byproduct $[3,4]$. However, since $\mathrm{H}_{2} \mathrm{O}_{2}$ is generally supplied as an aqueous solution, the use of $\mathrm{H}_{2} \mathrm{O}_{2}$ is often a problem in cases in which substrates are immiscible in water. In such cases, addition of an amphiphilic solvent (co-solvent) and/or vigorous agitation of the reaction mixture to make an emulsion for achieving sufficient interaction of $\mathrm{H}_{2} \mathrm{O}_{2}$ with both catalyst(s) and substrate(s) are often required.

We have proposed a new concept of a heterogeneous catalytic system for driving a reaction between a water-immiscible organic compound(s) and aqueous reagent(s) using a solid catalyst without a co-solvent or mechanical agitation [5-8]. For this system, we have prepared solid particles that could assemble at the liquid-liquid phase boundary by partial modification of external surfaces with alkylsilyl groups. It was found that titanium oxide-loaded $\mathrm{NaY}$ zeolite and silica $\left(\mathrm{SiO}_{2}\right)$ particles partially covered with alkylsilyl groups efficiently catalyzed epoxidation of terminal linear alkenes using aqueous $\mathrm{H}_{2} \mathrm{O}_{2}$ even without agitation. The reaction system is thus named "phase-boundary catalysis (PBC)".

We previously reported in detail phenomenological aspects of PBC for epoxidation of terminal linear alkenes [5,6], asymmetric surface structures of catalyst particles [7], and local structures of loaded titanium species [8]. Results of these studies lead to predictions to extend $\mathrm{PBC}$ to other organic reactions in order to obtain information on availability and limitations and to obtain mechanistic insights. In this paper, we describe the catalytic properties of a titanium oxide-loaded $\mathrm{SiO}_{2}$-based phase-boundary 
catalyst for oxidation of various hydrophobic alcohols using $\mathrm{H}_{2} \mathrm{O}_{2}$. We focus on oxidation of relatively bulky alcohols that are difficult to use for well-known titanium-containing microporous materials such as titanium silicalite, TS-1, and related materials [9-12] because of their limitation of pore size.

\section{Experimental}

\subsection{Materials}

A nonporous silica (Degussa Aerosil 200) was supplied from Nippon Aerosil and used as a support. Titanium(IV) ethoxide (Ti(OEt) 4 , 95\%) and n-octadecyltrimethoxysilane (ODMS, 95\%) were purchased from GELEST and used without further purification. Aqueous hydrogen peroxide $\left(\mathrm{H}_{2} \mathrm{O}_{2}\right.$, ca. 30\%) was purchased form Wako Pure Chemical. All other organic reagents were purified by standard procedures before use [13].

\subsection{Catalyst preparation}

Amphiphilic w/o- $\mathrm{Ti} / \mathrm{SiO}_{2}$ particles were prepared according to a procedure reported previously [8]. Three grams of silica was added to $150 \mathrm{~cm}^{3}$ of 2-propanol solution containing $145 \mathrm{mg}$ of $\mathrm{Ti}(\mathrm{OEt})_{4}$ under a dry argon atmosphere. After stirring the mixture for $3 \mathrm{~h}$ at room temperature, the solid was collected by centrifugation, dried at $383 \mathrm{~K}$ for $2 \mathrm{~h}$ under vacuum, and calcined at $773 \mathrm{~K}$ for $6 \mathrm{~h}$. The resulting powder is labeled $\mathrm{w}-\mathrm{Ti} / \mathrm{SiO}_{2}$. To $10 \mathrm{~cm}^{3}$ of toluene containing $1 \mathrm{mmol}$ of ODMS, $0.5 \mathrm{~g}$ of $\mathrm{w}-\mathrm{Ti} / \mathrm{SiO}_{2}$ thoroughly mixed with water $(16.7 \mathrm{wt} . \%)$ was added, and the suspension was shaken for $2 \mathrm{~min}$ at room temperature. After the addition of triethylamine (1 mmol), 
the suspension was further shaken for $10 \mathrm{~min}$ at room temperature. Then the solid was collected by centrifugation, washed twice with $10 \mathrm{~cm}^{3}$ of ethanol, and dried at $383 \mathrm{~K}$ for $2 \mathrm{~h}$ under vacuum. The thus-obtained white powder is labeled w/o- $\mathrm{Ti} / \mathrm{SiO}_{2}$. By colorimetric analysis of the samples using 1,2-dihydroxy-3,5-benzenedisulfonic acid disodium salt (Tiron), the titanium content was determined to be $158 \mu \mathrm{mol}$ per $1 \mathrm{~g}$ of catalyst.

\subsection{Characterization}

Thermogravimetry-differential thermal analysis (TG-DTA) was carried out using Bruker 2000A TG-DTA in air (flow rate: $100 \mathrm{~cm}^{3} \mathrm{~min}^{-1}$ ). Typically, ca. $10 \mathrm{mg}$ of a sample was heated in a platinum crucible from room temperature to $1073 \mathrm{~K}$, using heating ramps of $5 \mathrm{~K} \mathrm{~min}^{-1}$ up to $473 \mathrm{~K}$ and $10 \mathrm{~K} \mathrm{~min}^{-1}$ up to $1073 \mathrm{~K}$. BET surface area was measured at $77 \mathrm{~K}$ using a Quantachrome AUTOSORB-1 automated gas sorption system after drying at $423 \mathrm{~K}$ for $12 \mathrm{~h}$. Amount of titanium species leached after reaction was determined by using a Perkin-Elmer OPTIMA 3000-XL inductively coupled plasma (ICP) emission spectrometer. The amounts of $\mathrm{H}_{2} \mathrm{O}_{2}$ before and after

the reaction were determined by a standard titration method with $0.02 \mathrm{~mol} \mathrm{dm}^{-3}$ of aqueous potassium permanganate $\left(\mathrm{KMnO}_{4}\right.$, Wako).

\subsection{Oxidation of alcohols}

Typical procedures for oxidation of alcohols with aqueous $\mathrm{H}_{2} \mathrm{O}_{2}$ are as follows. To a cylindrical reaction vessel $(2 \mathrm{~cm}$ in diameter) with a reflux condenser, $8 \mathrm{mmol}$ of alcohol, $67 \mathrm{mg}$ of w/o-Ti/ $\mathrm{SiO}_{2}$ (corresponding to $0.01 \mathrm{mmol}$ of titanium) and $3 \mathrm{~cm}^{3}$ of toluene were successively added. After injection of $1.8 \mathrm{~cm}^{3}$ of aqueous $\mathrm{H}_{2} \mathrm{O}_{2}$ to the mixture, reactions were performed for $16 \mathrm{~h}$ without mechanical agitation. The reaction 
temperature was kept at $333 \mathrm{~K}$ by the use of a thermostatted oil bath. When necessary, the reaction mixture was stirred with a magnetic stirrer. Amounts of products were determined using Shimadzu GC 2010 and GC-14B gas chromatographs equipped with flame ionization detectors and capillary columns of DB-5 and TC-FFAP, respectively.

\section{Results and Discussion}

\subsection{Structural characteristics of modified particles}

Figure 1 shows the $\mathrm{TG}$ and DTA curves of $\mathrm{w}-\mathrm{Ti} / \mathrm{SiO}_{2}$ and $\mathrm{w} / \mathrm{o}-\mathrm{Ti} / \mathrm{SiO}_{2}$ samples measured in air in the temperature range of r.t.-1073 K. The TG curve of w-Ti/ $\mathrm{SiO}_{2}$ indicates a slight weight loss below $400 \mathrm{~K}$ and no further weight loss up to $1073 \mathrm{~K}$. The weight loss is attributable to dehydration and desorption of water. On the other hand, w/o-Ti/ $\mathrm{SiO}_{2}$ showed an additional large weight loss between ca. $500 \mathrm{~K}$ and ca.773 $\mathrm{K}$ in the TG curve. Since the weight loss was accompanied by a major exothermic event starting at ca. $500 \mathrm{~K}$ in the DTA curve, it was ascribed to combustion of surface-grafted alkylsilyl groups on the surface of w/o-Ti/ $\mathrm{SiO}_{2}$. Assuming that the remaining powder above $773 \mathrm{~K}$ is composed of a mixture of $\mathrm{SiO}_{2}$ and a small amount of loaded titanium(IV) oxide, the amount of alkylsilyl groups on w/o- $\mathrm{Ti} / \mathrm{SiO}_{2}$ was estimated to be $380 \mu \mathrm{mol}$ per unit weight of $\mathrm{w} / \mathrm{o}-\mathrm{Ti} / \mathrm{SiO}_{2}$. From the reported cross section of an octadecylsilyl group $\left(0.226 \mathrm{~nm}^{2}\right)$ [14], ca. $1.4 \mathrm{mmol}$ of alkylsilyl groups can be attached to the surface of w/o-Ti/ $/ \mathrm{SiO}_{2}$ having a surface area of $200 \mathrm{~m}^{2}$. The maximum amount of alkylsilyl groups that can be attached to the w/o- $\mathrm{Ti} / \mathrm{SiO}_{2}$ surface was also estimated using the density of surface hydroxyl groups of the $\mathrm{SiO}_{2}$ powders used (2.7 hydroxyls $\mathrm{nm}^{-2}$ ) [15]. Assuming that all of the alkylsilyl groups were attached through the reaction with surface hydroxyl, the maximum was estimated to be 
ca. $900 \mu \mathrm{mol}$ per unit weight of w/o-Ti/ $\mathrm{SiO}_{2}$. Although there is a significant difference between these estimations, it is indicated qualitatively that more than half of the surface hydroxyl groups remained on each $\mathrm{w} / \mathrm{o}-\mathrm{Ti} / \mathrm{SiO}_{2}$ particle. The presence of an appreciable amount of surface hydroxyl groups is also suggested by the weight loss below $400 \mathrm{~K}$ due to desorption of $\mathrm{H}_{2} \mathrm{O}$ in the TG curve of w/o-Ti/ $\mathrm{SiO}_{2}$ shown in Fig. 1(b). Such low coverage of alkylsilyl groups is thought to be due to the addition of a small amount of water just before grafting of a hydrophobic alkylsilylation agent. Since the hydrophilic $\mathrm{w}-\mathrm{Ti} / \mathrm{SiO}_{2}$ particles aggregated by capillary force of water and since the binding water between the particles prevents insertion of the agent into the aggregates, alkylsilyl groups can only be grafted on the outer parts of aggregates. Therefore, the surface of $\mathrm{w} / \mathrm{o}-\mathrm{Ti} / \mathrm{SiO}_{2}$ was expected to be amphiphilic; one side of the surface of w/o- $\mathrm{Ti} / \mathrm{SiO}_{2}$ was covered with alkylsilyl groups and the remainder retained its original hydrophilic surface. Indeed, through fluorescence microscopy of the modified $\mathrm{NaY}$ particles, the remaining surface hydroxyl groups of which were labeled with a fluorescence dye, we have revealed the presence of both hydroxyl and alkylsilyl surfaces on each particle [7].

Upon addition of $\mathrm{w}-\mathrm{Ti} / \mathrm{SiO}_{2}$ samples to a dual-phase mixture of toluene and water, w- Ti/ $/ \mathrm{SiO}_{2}$ was only dispersed in water due to its hydrophilic surface property. On the other hand, in the case of $\mathrm{w} / \mathrm{o}-\mathrm{Ti} / \mathrm{SiO}_{2}$, most of the particles were assembled at the liquid-liquid phase boundary. As reported previously $[5-8,16]$, this is a phenomenological indication of amphiphilic character, having both hydrophobic and hydrophilic faces, of oxide particles. Based on these results and observations, $\mathrm{w} / \mathrm{o}-\mathrm{Ti} / \mathrm{SiO}_{2}$ is thought to be assembled at the phase boundary of the water-toluene dual-phase mixture by facing its hydrophobic octadecylsilylated side to the organic phase and its hydrophilic side to the aqueous phase. Further details of amphiphilic characters of particles prepared by the same procedure and their applications will be described elsewhere [17]. 


\subsection{Catalytic activity for oxidation of benzyl alcohol with aqueous $\mathrm{H}_{2} \mathrm{O}_{2}$}

Table 1 summarizes catalytic properties of $\mathrm{w}-\mathrm{Ti} / \mathrm{SiO}_{2}$ and $\mathrm{w} / \mathrm{o}-\mathrm{Ti} / \mathrm{SiO}_{2}$ for oxidation of benzyl alcohol under various conditions. Both w-Ti/ $\mathrm{SiO}_{2}$ and w/o-Ti $/ \mathrm{SiO}_{2}$ particles suspended and agitated in the dual-phase mixture of aqueous $\mathrm{H}_{2} \mathrm{O}_{2}$ and toluene containing benzyl alcohol gave benzaldehyde with production of other probable by-products, mainly benzoic acid (entries 1 and 2). When these particles were absent, much smaller amounts of products were obtained (entry 3 ), indicating that the reaction was induced by these catalysts. However, it was noted, especially for $\mathrm{w}-\mathrm{Ti} / \mathrm{SiO}_{2}$, that a large amount of loaded titanium was leached from the surface into the aqueous phase, as determined from the results of ICP analysis for the aqueous phase after the reaction. When aqueous $\mathrm{H}_{2} \mathrm{O}_{2}$ and benzyl alcohol were added to the aqueous phase that was corrected after the reaction of entry 1 and stirring the mixture under the same reaction conditions, an appreciable amount of benzaldehyde was produced (entry 4). Thus, observed liberation of benzaldehyde from the w-Ti/ $\mathrm{SiO}_{2}$ suspension was mainly induced by such leached titanium species. Although the w/o- $\mathrm{Ti} / \mathrm{SiO}_{2}$ suspension gave a ca. 1.5-times larger amount of benzaldehyde than did the $\mathrm{w}-\mathrm{Ti} / \mathrm{SiO}_{2}$ suspension and leaching of titanium was suppressed to some extent (entry 2), this may also include the influence of dissolved titanium species. On the other hand, when the reaction was performed under static conditions, i.e., PBC conditions, a relatively large amount of benzaldehyde was produced from the w/o- $\mathrm{Ti} / \mathrm{SiO}_{2}$ suspension (entry 6). In this case, moreover, much less leaching was observed, while the w- $\mathrm{Ti} / \mathrm{SiO}_{2}$ suspension showed the same behavior as that of the above agitation system; reaction by leached titanium might be predominant (entries 5 and 7). The remaining aqueous solution of w/o-Ti/ $/ \mathrm{SiO}_{2}$ after the reaction under such static conditions did not give a detectable amount of benzaldehyde, as expected (entry 8). In addition, when the amount of 
catalyst was decreased to $3.4 \mathrm{mg}$ (corresponding to $0.5 \mu \mathrm{mol}$ of $\mathrm{Ti}$ ), the turnover number (TON) of benzaldehyde based on Ti approached ca. 530 (entry 9). These results imply that when the reaction was performed under $\mathrm{PBC}$ conditions, modification with alkylsilyl groups brought about sufficient stability of titanium active sites to leaching. Accordingly, it could be confirmed that the $\mathrm{PBC}$ using w/o- $\mathrm{Ti} / \mathrm{SiO}_{2}$ was a heterogeneous catalytic system for selective oxidation of benzyl alcohol (see below).

\subsection{Catalytic properties for oxidation of various hydrophobic alcohols}

In order to examine the availability of the w/o- $\mathrm{Ti} / \mathrm{SiO}_{2}$-based $\mathrm{PBC}$, oxidation of various aromatic and cyclic alkyl alcohols using aqueous $\mathrm{H}_{2} \mathrm{O}_{2}$ was performed. The results are summarized in Table 2. Primary benzylic alcohols were efficiently converted into corresponding aldehydes, and their reaction rates were slightly dependent on substituents $\left(-\mathrm{Cl},-\mathrm{OCH}_{3}\right.$, and $\left.-\mathrm{CH}_{3}\right)$ and their positions $\left(p-, m-\right.$, and $\left.o^{-}\right)$(entries 1-6). Similarly, secondary benzylic alcohols were also oxidized to corresponding ketones in relatively high selectivity (entries 7-8). On the other hand, poor selectivities for oxidation of allylic alcohols such as cinnamyl alcohol was obtained (entry 9), owing to the activity of loaded titanium sites for epoxidation [12,18-20]. It was noted that the catalytic system could be utilized for oxidation of secondary cyclic alcohols such as cyclohexanol and cyclooctanol, which are relatively inactive toward oxidation, to corresponding ketones (entries 10-11). Oxidation of a series of aliphatic alcohols has been widely examined using microporous titanosilicalites such as TS-1 [9-11]. However, these bulky alcohols reported here were not employed as substrates in such titanium-based heterogeneous catalysts owing to the limitation of their pore sizes. Hence, although overall rates were not satisfactory, the present $\mathrm{PBC}$ system might enable a titanium-based catalyst to be used for oxidation of various bulky alcohols. 


\subsection{Role of alkylsilyl groups}

As previously investigated using $\mathrm{Ti}$ K-edge X-ray absorption near-edge fine structure (XANES) analysis [8], the loaded titanium species on w/o- $\mathrm{Ti} / \mathrm{SiO}_{2}$ were mainly those with tetrahedral coordination $\left(\mathrm{T}_{\text {tet }}\right)$ with a small content of octahedrally coordinated ones $\left(\mathrm{T}_{\mathrm{oct}}\right)$. The former was attributable to the isolated titanium and the latter included titanium dimers, oligomers, and/or bulk $\left(\mathrm{TiO}_{2}\right)$-like microclusters [21-24]. The efficiency of $\mathrm{H}_{2} \mathrm{O}_{2}$ utilized for the reaction measured in some selected samples was estimated to be below $20 \%$ (data not shown). This suggests unproductive decomposition (or auto-decomposition) of $\mathrm{H}_{2} \mathrm{O}_{2}$ on these $\mathrm{T}_{\text {oct }}$ sites under a large excess of $\mathrm{H}_{2} \mathrm{O}_{2}$ [8], and thereby the active species might be ascribed to $\mathrm{T}_{\text {tet. }}$ It has also been clarified in our previous study using ultraviolet and visible-light diffuse reflectance (UV-Vis-DR) spectroscopy in relation to catalytic activity [8] that there are three types of $\mathrm{T}_{\text {tet }}$ on w/o- $\mathrm{Ti} / \mathrm{SiO}_{2}$. These are $\mathrm{T}_{\text {tet }}$ anchoring an acidic hydroxyl $\left(\mathrm{T}_{\text {tet }}(\mathrm{OH})\right)$ located on the hydrophilic and hydrophobic surfaces $\left(\mathrm{w}-\mathrm{T}_{\text {tet }}(\mathrm{OH})\right.$ and $\mathrm{o}-\mathrm{T}_{\text {tet }}(\mathrm{OH})$ ) and $\mathrm{T}_{\text {tet }}$ directly attached to an alkylsilyl group $\left(\mathrm{T}_{\text {tet }}(\mathrm{OSiR})\right)$. The latter was formed via reaction of an acidic hydroxyl of $\mathrm{T}_{\text {tet }}(\mathrm{OH})$ with an alkylsilane agent on the hydrophobic surface. Schematic structures of these titanium sites are shown in Fig. 2. The results of oxidation of benzyl alcohol summarized in Table 1 suggest that ${ }_{\mathrm{w}}-\mathrm{T}_{\text {tet }}(\mathrm{OH})$ sites probably do not contribute to the heterogeneous catalytic property of w/o-Ti/ $\mathrm{SiO}_{2}$ because these must be present on $\mathrm{w}-\mathrm{Ti} / \mathrm{SiO}_{2}$ as sole $\mathrm{T}_{\text {tet }}$ sites. As described above, $\mathrm{T}_{\text {tet }}$ sites were not stable under the present reaction conditions, i.e., oxidation proceeded by mainly leached titanium species (Table 1, entries 4 and 7). Thus, two probable species located on the hydrophobic surface of $\mathrm{w} / \mathrm{o}-\mathrm{Ti} / \mathrm{SiO}_{2}, \mathrm{o}-\mathrm{T}_{\text {tet }}(\mathrm{OH})$ and $\mathrm{T}_{\text {tet }}(\mathrm{OSiR})$, might induce heterogeneous catalytic activity, though it is not clear at present that whether one of them is active or both are active. According to these speculations, surface-grafted alkylsilyl groups were considered to give particles two beneficial effects for the use of a 
heterogeneous catalyst. One is to give hydrophobicity of $\mathrm{T}_{\text {tet }}$ sites inducing effective contact with hydrophobic alcohols, and the other is to prevent leaching by covering with siloxane networks of alkylsilylation agents.

\section{Conclusions}

It was found that amphiphilic $\mathrm{SiO}_{2}$ particles loaded with titanium(IV) oxide species acted as a catalyst for the oxidation of benzylic and cyclic alkyl alcohols using aqueous $\mathrm{H}_{2} \mathrm{O}_{2}$ under static conditions, i.e., phase boundary catalytic conditions. To the best of our knowledge, this is the first example of oxidation of bulky hydrophobic alcohols using aqueous $\mathrm{H}_{2} \mathrm{O}_{2}$ over a heterogeneous titanium catalyst. Such catalytic functions were probably realized by effective contact of catalyst particles with $\mathrm{H}_{2} \mathrm{O}_{2}$ and hydrophobic alcohols, respectively, as well as the effect of stabilization of active titanium sites by surface-grafted alkylsilyl groups. The results should provide useful information for an alternative strategy to design catalytic materials.

\section{Acknowledgements}

The authors are grateful to Nippon Aerosil Co., Ltd. for supplying silica samples. This research was partly supported by RITE research grants. Professor K. Kaneda and K. Ebitani (Osaka University) are acknowledged for their stimulating suggestions and discussion.

\section{References}


[1] R.A. Sheldon, J.K. Kochi, Metal-Catalyzed Oxidations of Organic Compounds, Academic Press, New York, 1981.

[2] M. Hudlicky, Oxidation in Organic Chemistry, ACS monograph 186, American Chemical Society, Washington, DC, USA, 1990.

[3] Catalytic Oxidations with Hydrogen Peroxide as Oxidant, ed. G. Strukul, Kluwer Academic, Dordrecht, The Netherlands, 1992.

[4] C. W. Jones, Application of Hydrogen Peroxide and Derivatives, Royal Society of Chemistry, Cambridge, 1999.

[5] H. Nur, S. Ikeda, B. Ohtani, Chem. Commun. (2000) 2235.

[6] H. Nur, S. Ikeda, B. Ohtani, J. Catal. 204 (2001) 402.

[7] S. Ikeda, H. Nur, T. Sawadaishi, K. Ijiro, M. Shimomura, B. Ohtani, Langmuir 17 (2001) 7976.

[8] K. Ikeue, S. Ikeda, A. Watanabe, B. Ohtani, Phys. Chem. Chem. Phys. 6 (2004) 2523 .

[9] A.J.H.P. van der Pol, J.H.C. van Hooff, Appl. Catal. A 106 (1993) 97.

[10] F. Maspero, U. Romano, J. Catal. 146 (1994) 476.

[11] H. Hayashi, K. Kikawa, Y. Murai, N. Shigemoto, S. Sugiyama, K. Kawashioro, Catal. Lett. 36 (1996) 99.

[12] L.J. Davies, P. McMorn, D. Bethell, P.C.B. Page, F. King, F.E. Hancock, G.J. Hutchings, J. Mol. Catal. A: Chem. 165 (2001) 243.

[13] Purification of Laboratory Chemicals, 5th ed., eds. W.L.F. Armarego and C.L.L. Chai, Butterworth-Heinemann, Oxford, 2003.

[14] A.Y. Fadeev, R. Helmy, S. Marcinko, Langmuir 18 (2002) 7521.

[15] M. Fuji, T. Takei, T. Watanabe, M. Chikazawa, Colloids Surf. A 154 (1999) 13.

[16] S. Ikeda, Y. Kowata, K. Ikeue, M. Matsumura, B. Ohtani Appl. Catal. A, 265 (2004) 69. 
[17] S. Ikeda, K. Ikeue, K. T. Kitani, S. Ishino, Y. Saito, M. Matsumura, B. Ohtani, J. Mater. Chem. submitted.

[18] M.G. Clerici, P. Ingallina, J. Catal. 140 (1993) 71.

[19] T. Tatsumi, K.A. Koyano, N. Igarashi, Chem. Commun. (1998) 325.

[20] P. Wu, T. Tatsumi, Chem. Commun. (2002) 1026.

[21] L. Marchese, T. Maschmeyer, E. Gianotti, S. Coluccia, J. M. Thomas, J. Phys.

Chem. B 101 (1997) 8836.

[22] C. Lamberti, S. Bordiga, D. Arduino, A. Zecchina, F. Geobaldo, G. Spanó, F.

Genoni, G. Petrini, A. Carati, F. Villain, G. Vlaic, J. Phys. Chem. B 102 (1998) 6382.

[23] L. Marchese, E. Gianotti, V. Dellarocca, T. Maschmeyer, F. Rey, S. Coluccia, J.M.

Thomas, Phys. Chem. Chem. Phys., 1 (1999) 585.

[24] M.E. Raimondi, E. Gianotti, L. Marchese, G. Martra, T. Maschmeyer, J.M. Seddon, S. Coluccia, J. Phys. Chem. B 104 (2000) 7102.

\section{Figure Captions}

Fig. 1. TG-DTA curves of (a) $\mathrm{w}-\mathrm{Ti} / \mathrm{SiO}_{2}$ and (b) $\mathrm{w} / \mathrm{o}-\mathrm{Ti} / \mathrm{SiO}_{2}$.

Fig. 2. Schematic illustrations of local structures and distributions of tetrahedral titanium oxide species on a w/o-Ti/SiO ${ }_{2}$ sample. (i) $\mathrm{T}_{\text {tet }}(\mathrm{OSiR})$ sites located on the hydrophobic surface, (ii) $\mathrm{T}_{\text {tet }}(\mathrm{OH})$ sites located on both hydrophilic and hydrophobic surfaces $\left(\mathrm{w}-\mathrm{T}_{\text {tet }}(\mathrm{OH})\right.$ and $\mathrm{o}-\mathrm{T}_{\text {tet }}(\mathrm{OH})$, respectively). 


\section{Table 1.}

Oxidation of benzyl alcohol with $\mathrm{H}_{2} \mathrm{O}_{2}$ in water-toluene dual-phase system ${ }^{\mathrm{a}}$

\begin{tabular}{ccccccc}
\hline entry & catalyst & condition & $\begin{array}{c}\text { aldehyde }^{\mathrm{b}} \\
/ \text { mmol }\end{array}$ & $\begin{array}{c}\text { select. }^{\mathrm{c}} \\
/ \%\end{array}$ & $\begin{array}{c}\text { leaching }^{\mathrm{d}} \\
/ \%\end{array}$ & TON \\
\hline 1 & w-Ti/ $\mathrm{SiO}_{2}$ & stirr $^{\mathrm{e}}$ & 0.98 & 89 & 25 & 98 \\
2 & w/o-Ti/ $/ \mathrm{SiO}_{2}$ & stirr $^{\mathrm{e}}$ & 1.32 & 74 & 15 & 132 \\
3 & none & stirr $^{\mathrm{e}}$ & 0.08 & 100 & - & - \\
4 & soln.-1 & stirr $^{\mathrm{e}}$ & 0.61 & 85 & - & - \\
5 & w-Ti/ $/ \mathrm{SiO}_{2}$ & stat $^{\mathrm{f}}$ & 0.80 & 96 & 25 & 80 \\
6 & w/o-Ti/ $\mathrm{SiO}_{2}$ & stat $^{\mathrm{f}}$ & 1.29 & 97 & 2 & 129 \\
7 & soln.-2 & stirr $^{\mathrm{e}}$ & 0.61 & 85 & - & - \\
8 & soln.-3 & stirr $^{\mathrm{i}}$ & $0^{\mathrm{k}}$ & - & - & - \\
9 & w/o-Ti/ $\mathrm{SiO}_{2}{ }^{\mathrm{j}}$ & stat $^{\mathrm{f}}$ & 0.26 & 100 & $0^{\mathrm{k}}$ & 530 \\
\hline
\end{tabular}

${ }^{\mathrm{a}}$ All reactions were carried out at $333 \mathrm{~K}$ for $16 \mathrm{~h}$ with benzyl alcohol $(8 \mathrm{mmol})$, toluene $\left(3 \mathrm{~cm}^{3}\right), 30 \% \mathrm{H}_{2} \mathrm{O}_{2}\left(1.8 \mathrm{~cm}^{3}\right)$, and catalyst $(67 \mathrm{mg}) .{ }^{\mathrm{b}}$ Benzaldehyde. ${ }^{\mathrm{c}}$ Selectivity for benzaldehyde production defined as the percentage of the aldehyde yield to the total amount of detected products. The percentage of titanium in the solution after the reaction. ${ }^{\mathrm{e}}$ Reaction was carried out with vigorous mechanical agitation. ${ }^{\mathrm{f}}$ Reaction was carried out without agitation. ${ }^{\mathrm{g}}$ The aqueous phase of entry 1 after the reaction was used. ${ }^{\mathrm{h}}$ The aqueous phase of entry 5 after the reaction was used. ${ }^{\mathrm{i}}$ The aqueous phase of entry 6 after the reaction was used. ${ }^{\mathrm{j}} 3.4 \mathrm{mg}$ of catalyst was used. ${ }^{\mathrm{k}}$ Not detected $\left(<10^{-3}\right.$ $\mu \mathrm{mol})$. 


\section{Table 2.}

Oxidation of various alcohols catalyzed by w/o- $\mathrm{Ti}-\mathrm{SiO}_{2}$ using $\mathrm{H}_{2} \mathrm{O}_{2}$ as an oxidant $^{\mathrm{a}}$

(m)

${ }^{\mathrm{a}}$ All reactions were carried out at $333 \mathrm{~K}$ for $16 \mathrm{~h}$ with alcohol $(8 \mathrm{mmol})$, toluene ( 3 $\left.\mathrm{cm}^{3}\right), 30 \% \mathrm{H}_{2} \mathrm{O}_{2}\left(1.8 \mathrm{~cm}^{3}\right)$, and catalyst $(67 \mathrm{mg})$. ${ }^{\text {b }}$ Yield of the produced aldehyde determined by GC using internal standard technique. ${ }^{\mathrm{c}}$ Selectivity for aldehyde production defined as the percentage of the aldehyde yield to the total amount of products. 


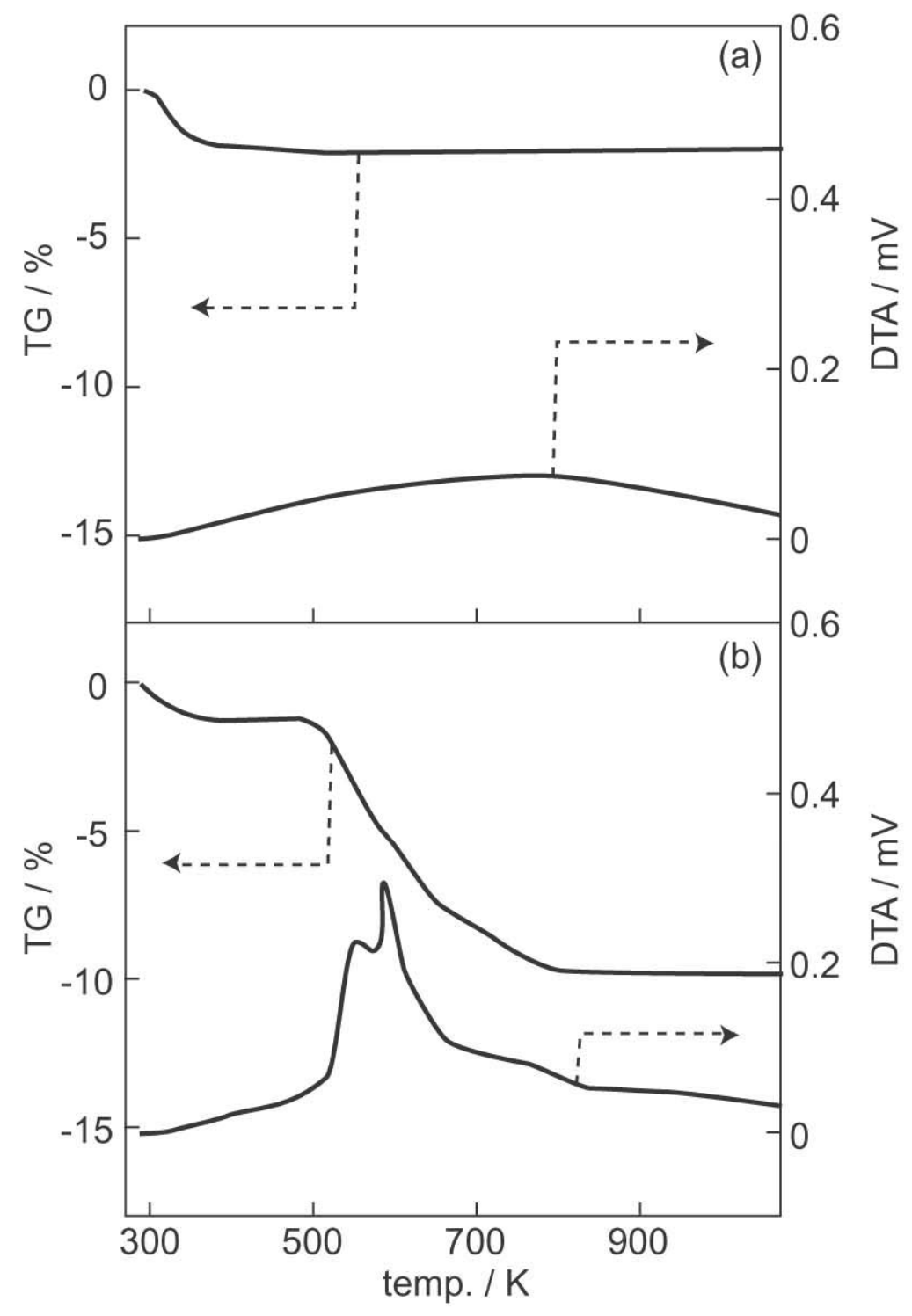

Fig. 1. K.-m. Choi et al. 


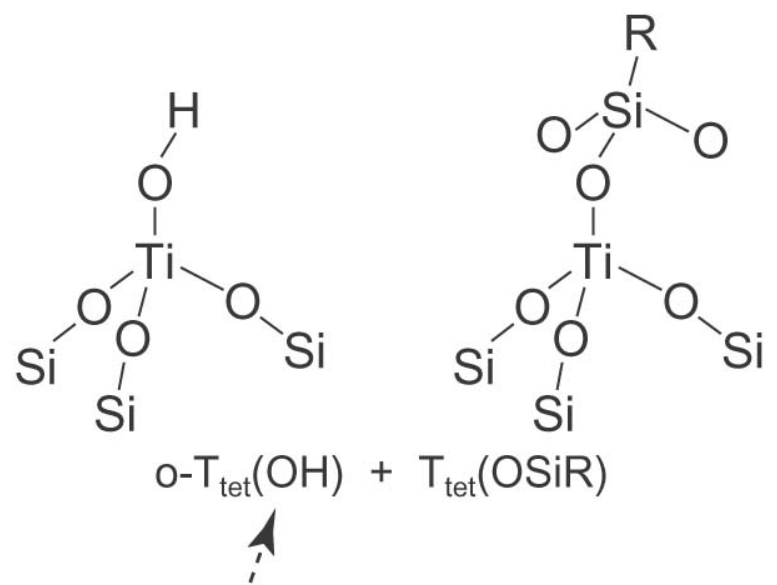

hydrophobic surface
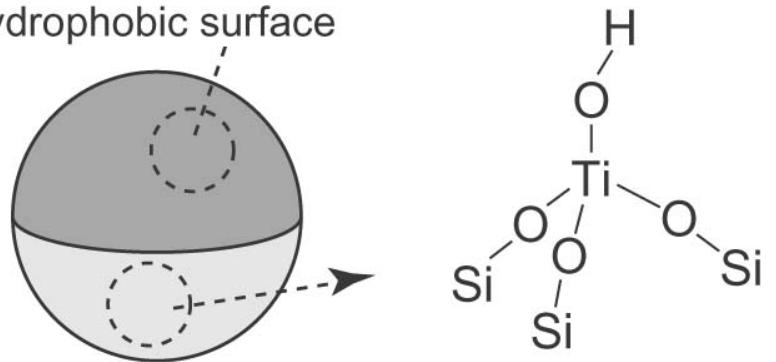

hydrophilic surface

$w-\mathrm{T}_{\text {tet }}(\mathrm{OH})$

Fig. 2. K.-m. Choi et al. 